\title{
Severe Dengue with Rapid Onset Dementia, Apraxia of Speech and Reversible Splenial Lesion
}

\author{
Manju Mathew ${ }^{1} \quad$ Reji Thomas ${ }^{2}$ Vijayalekshmi S. ${ }^{2}$ \\ 1Department of Critical Care, Pushpagiri Medical College Hospital, \\ Pathanamthitta, Kerala, India \\ 2Department of Neurology, Pushpagiri Medical College Hospital, \\ Pathanamthitta, Kerala, India
}

J Neurosci Rural Pract 2021;12:608-610.

Dengue has several neurological manifestations of which reversible splenial lesion of the corpus callosum (RESLES) is a rare one. RESLES is characterized by mild encephalopathy and reversible splenial lesions on magnetic resonance imaging (MRI) that usually resolve in 2 to 4 weeks without any sequelae..$^{1-3}$

A 32-year-old gentleman without comorbidities presented with fever, headache, vomiting and myalgia for 7 days followed by gait unsteadiness, language impairment with articulation errors and mild confusion. His Glasgow coma scale score was 14/15 and had normal vitals except for oxygen saturation of 93\%. He scored 17/30 on Montreal Cognitive Assessment with impairments in clock drawing, trail making, attention, memory, orientation and language domains. He had significant impairment in frontal assessment battery (score 8/18) and Trail A and B tests. He was dysarthric with normal comprehension noted on auditory word recognition and sequential commands. Speech was significantly distorted with incorrect speech sounds, groping for the right sounds, trial and error attempts and omission of certain phrases during repetition and paragraph reading. There was undue stress on certain syllables with loss of prosody. He could, however, show how to blow out a match correctly and do other oral gestures. Naming and writing were also normal. There was mild incoordination of the limbs and gait ataxia. Laboratory results showed neutropenia, thrombocytopenia, raised liver enzymes and high blood sugar. Dengue nonstructural protein 1 antigen, immunoglobulin $\mathrm{M}$, and immunoglobulin $G$ were positive. MRI brain revealed an isolated hyperintense, boomerang-shaped lesion involving splenium of the corpus callosum in diffusion-weighted imaging (DWI), and fluid-attenuated inversion recovery (FLAIR) sequences ( - Fig. 1). Both clinical and radiological abnormalities resolved completely within a month.

published online

May 10, 2021
DOI https://doi.org/

$10.1055 / \mathrm{s}-0041-1729476$ ISSN 0976-3147

\begin{abstract}
Address for correspondence Reji Thomas, MD, DM, Department of Neurology, Pushpagiri Medical College Hospital, Thiruvalla, Pathanamthitta, Kerala 689101, India

(e-mail: rejithomas_doc@yahoo.com; dr.tresamaria@gmail.com).
\end{abstract}

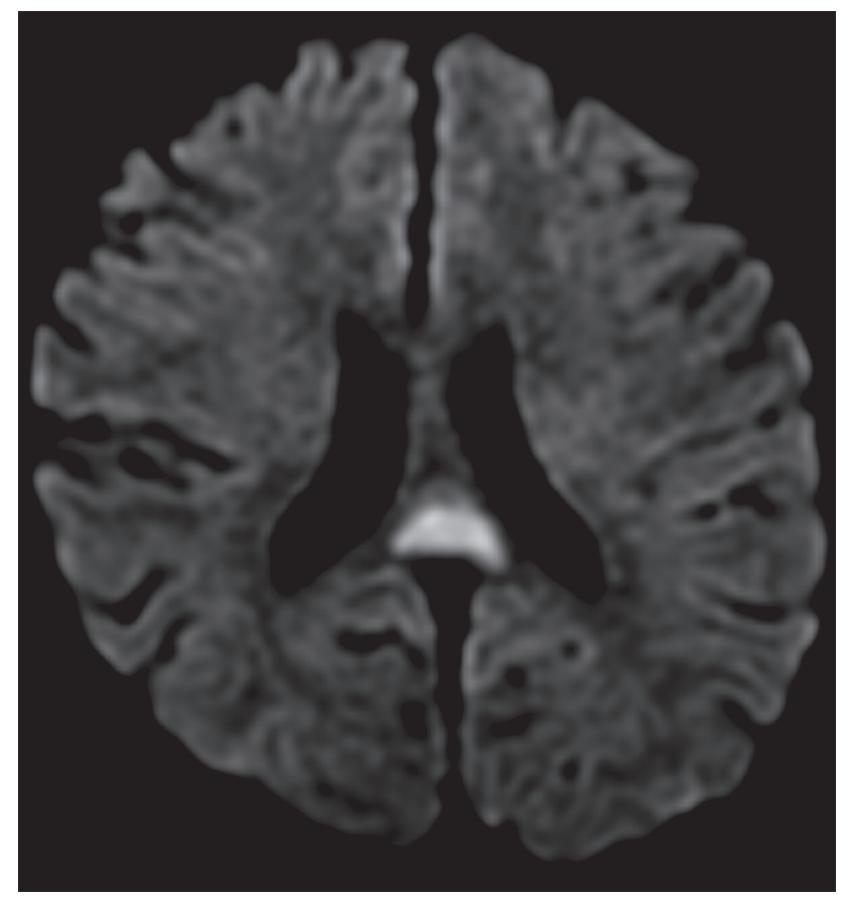

Fig. 1 Magnetic resonance imaging brain diffusion-weighted image shows hyperintensity in the splenium of the corpus callosum.

Severe dengue was diagnosed based on thrombocytopenia, plasma leakage, liver and central nervous system involvement. ${ }^{4}$ Unlike the mild cognitive impairment reported in $90 \%$ of RESLES cases, our patient presented with a wide range of cognitive impairments that included apraxia of speech, executive dysfunction, impairment in attention and memory along with mild gait ataxia and dysarthria. RESLES has been reported in association with several conditions that cause cytotoxic edema of the splenium. ${ }^{2.5,6}$ (c) 2021. Association for Helping Neurosurgical Sick People.

This is an open access article published by Thieme under the terms of the Creative Commons Attribution-NonDerivative-NonCommercial-License, permitting copying and reproduction so long as the original work is given appropriate credit. Contents may not be used for commercial purposes, or adapted, remixed, transformed or built upon. (https://creativecommons.org/licenses/by-nc-nd/4.0/).

Thieme Medical and Scientific Publishers Pvt. Ltd. A-12, 2nd Floor, Sector 2, Noida-201301 UP, India 
Although dengue virus by itself may have caused RESLES in our case, it appears more likely to be multifactorial. Additional etiological factors reported to be directly associated with RESLES that may have been involved in this case are hyperglycemia, hypovolemia, vascular hyperpermeability and hepatic dysfunction. ${ }^{2,5}$ The widespread cognitive changes without the radiological features seen in dengue encephalitis such as bilateral symmetric changes in basal ganglia, thalamus, pons, temporal lobes or cerebellum support this view. ${ }^{7}$

Our case extends the spectrum of neurological abnormalities associated with reversible splenial lesions and severe dengue. Severe cognitive impairment and apraxia of speech may rarely occur in severe dengue without corresponding radiological abnormalities as in this case, and may be multifactorial. Diligent attention to associated systemic abnormalities will ensure good outcome in such situations.

Note

The authors state that this article submission conforms to the Declaration of Helsinki.

\section{Funding}

None.

\section{Authors' Contributions}

M.M. contributed in the collection of data, writing of the manuscript and references, formatting. R.T. contributed in writing of the manuscript and references, formatting, review. S.V. and M.P. performed article review and editing.

\section{Conflict of Interest}

None declared.

\section{References}

1 Zhang S, Ma Y, Feng J. Clinicoradiological spectrum of reversible splenial lesion syndrome (RESLES) in adults: a retrospective study of a rare entity. Medicine (Baltimore) 2015;94(6):e512

2 Starkey J, Kobayashi N, Numaguchi Y, Moritani T. Cytotoxic lesions of the corpus callosum that show restricted diffusion: mechanisms, causes, and manifestations. Radiographics 2017;37(2):562-576

3 Mathew T, Badachi S, Sarma GR, Nadig R. "Dot sign" in dengue encephalitis. Ann Indian Acad Neurol 2015;18(1):77-79

4 Dengue Guidelines for Diagnosis, Treatment, Prevention and Control. World Health Organization, Geneva; 2009

5 Kaino K, Kumagai R, Furukawa S, et al. Reversible splenial lesion syndrome with a hyperosmolar hyperglycemic state and neuroleptic malignant syndrome caused by olanzapine. J Diabetes Investig 2017;8(3):392-394

6 Mizutani AU, Shindo A, Arikawa S, et al. Reversible splenial lesion in a patient with new-onset refractory status epilepticus (NORSE) eNeurologicalSci 2020;18:100220

7 Soni BK, Das DSR, George RA, Aggarwal R, Sivasankar R. MRI features in dengue encephalitis: a case series in South Indian tertiary care hospital. Indian J Radiol Imaging 2017;27(2):125-128 